\title{
CONSCIENTIZAÇÃO AMBIENTAL COM ALUNOS DA EDUCAÇÃO INFANTIL DA ESCOLA DE ENSINO FUNDAMENTAL KINDERWELT DE AGUDO - RS
}

\author{
Daniele Jaqueline Link1, Luiz Ernani Bonesso de Araújo², \\ Elisane Maria Rampelotto, Clayton Hilling ${ }^{2}$ \\ ${ }^{1}$ Especialista em Educação Ambiental - UFSM \\ 2 Professores do Curso de Especialização em Educação Ambiental - UFSM
}

\section{RESUMO}

O presente trabalho se refere a um estudo que analisa o desenvolvimento de determinadas atividades voltadas à conscientização ambiental dos alunos da Educação Infantil, já que está é a primeira etapa da educação escolar. A pesquisa quer mostrar a viabilidade de implementar a Educação Ambiental na Educação Infantil, buscando o interesse das crianças pelos assuntos relacionados à questão ambiental. Para isso, foram oportunizadas atividades práticas e didáticas sobre os problemas ambientais, principalmente sobre o lixo que afeta nossas vidas. Entretanto, foi realizada uma pesquisa bibliográfica e de caráter qualitativa, desenvolvida entre os meses de agosto a outubro de 2011. A pesquisa foi desenvolvida na Escola de Ensino Fundamental Kinderwelt, na cidade de Agudo, RS. O público alvo da pesquisa foram os alunos do Maternal e da Pré-escola, totalizando o número de 29 crianças, com idade entre 2 a 6 anos. Os temas abordados foram de grande relevância para a aprendizagem das crianças o que resultou num bom desenvolvimento das atividades. Com este estudo, conclui-se que a Educação Ambiental pode ser desenvolvida na Educação infantil, pois as crianças estão sempre dispostas a novos conhecimentos, informações e reflexões sobre os assuntos ligados a Educação Ambiental, tornando-os conscientes e atentos a tudo o que acontece ao seu redor.

Palavras chaves: Educação Ambiental. Educação Infantil. Conscientização Ambiental.

\begin{abstract}
This work aims to become the pupils of the Infantile Education more awareness environmentally, considering that this is the first stage of the school education. The research will expose the viability of implanting the Environmental Education in the Infantile Education, attending the interest of the children in relation to these environmental subjects. For this were provided practical and didactical activities about the environmental problems mainly about the garbage that affects people's life to develop the idea of this study. However, there was achieved a bibliographic research of qualitative nature, it is exploratory developed during the months of August to October of 2011. The research was developed in the Elementary School Kinderwelt, in the city of Agudo, RS. The aim public of the research was the pupils of Maternal and of Pre-school, about 29 children, with the age from two to six years. Old the themes approached had great relevancy in children's learning that resulted in a good development of the activities. The conclusion of this study demonstrated that the Environmental Education can be developed in Infantile Education, because the children are always disposed to new knowledge, information and
\end{abstract}


reflection about the subjects related to the Environmental Education, with these exposes the children will become more awareness and attentive to all what happens around them.

Keyword: Environmental Education. Infantile Education. Environmental Awareness.

\section{INTRODUÇÂO}

Ao longo dos tempos, a humanidade cresceu de forma acelerada e isso ocasionou várias consequências ao meio ambiente. Um dos principais fatores de degradação ambiental ocorreu devido ao uso inadequado dos recursos naturais.

O homem sempre usou os recursos para atender as suas necessidades; antigamente usava estes recursos de forma equilibrada, sem prejudicar a natureza, só retirava aquilo que carecia para sua sobrevivência. Mas, com o passar dos tempos, esse equilíbrio desapareceu devido ao aumento da população, a alta tecnologia desenvolvida e ao exagerado consumo das pessoas. E isso acarretou numa demasiada utilização dos recursos naturais, em grande parte, explorados de forma imprópria.

Esse desequilíbrio ocasionado pelo homem demonstra que não se sente parte do meio ambiente; se ele continuar a destruir de forma inescrupulosa sem se preocupar com as consequências e efeitos de seus atos, poderá ocasionar a destruição do Planeta bem como a sua existência também.

A partir dessa realidade, devemos pensar em uma maneira de modificar as atitudes e comportamentos da sociedade perante o meio ambiente. E nada mais aplausível que começar na Educação Infantil, pois através da escola podemos modificar os conceitos pré-estabelecidos por nossa geração a respeito sobre a natureza e a sua utilização.

Surgiu, então, à necessidade de mudar esse quadro, e a Educação Ambiental é uma das maneiras de reverter essa situação, pois ela busca modificar valores, comportamentos, atitudes a fim de buscar qualidade de vida a todos os cidadãos e pensar num mundo sustentável, respeitando a natureza e os benefícios que oferece.

Mas, para que isso possa acontecer, é necessário mudar a atitude da população e é importante iniciar essa mudança nos primeiros anos de vida escolar da criança. Assim sendo, a Educação Infantil proporciona nessa primeira etapa de sua vida um desenvolvimento do saber, a criança está sempre disposta a aprender tudo e, portanto, devemos aproveitar esse momento para desenvolver o respeito ao meio, que é fundamental para a aprendizagem e que será levada por toda a vida, pois, além de entender, aprendem a valorizar e amar o meio ambiente.

Neste sentido, a escola é um dos primeiros espaços na qual a criança convive com outras pessoas, e é a primeira experiência de interação com a sociedade. Sua natureza, portanto, por si só, já é observatória e curiosa, e seu desenvolvimento se da através de descobertas que envolvem a escola e seu meio em que vive, estabelecendo relações de vivência com o mundo que a cerca.

Nesse contexto, nada mais importante que iniciar um trabalho de conscientização ambiental na Educação Infantil, por meio de sua inserção no currículo. As crianças de hoje são o nosso futuro, pois através de comportamentos ambientalmente corretos vivenciados na escola podem adquirir formação adequada e, em consequência, responsabilidade pelo meio ambiente.

Assim, desde a infância, estimuladas a tomar atitudes conscientes e compartilhar responsabilidades, no futuro; farão parte de uma sociedade mais justa, responsável e conscientizados de seus papéis como atores sociais. 


\section{METODOLOGIA}

Este trabalho tem como finalidade uma pesquisa com abordagem qualitativa. Realizou-se um estudo de caso com alunos da Educação Infantil da Escola de Ensino Fundamental Kinderwelt, na cidade de Agudo, Rio Grande do Sul.

Optou-se pela pesquisa qualitativa por ser exploratória, já que seu estudo foi realizado num ambiente escolar, num local de afinidades dinâmicas e complexas em constantes mudanças. A pesquisa estimula o pensamento sobre determinado tema e faz surgir de forma espontânea aspectos subjetivos que atinjam motivações conscientes de algum tema. Este tipo de pesquisa busca despertar certas percepções e entendimento sobre a natureza geral de uma questão em evidência, para buscar uma interpretação adequada sobre o assunto.

A pesquisa foi abordada de forma qualitativa, percorrendo a aprendizagem da criança em relação à conscientização ambiental integrando-a ao seu dia-a-dia, e dentro e fora do ambiente escolar.

Num primeiro momento, foi realizada a revisão bibliográfica sobre o tema abordado. Consultaram-se livros, monografias, teses e periódicos sobre a Educação Ambiental e a Educação Infantil. Num segundo momento, foi abordada a questão do lixo e as suas consequências em nossas vidas; e por último, os resultados dessa pesquisa bem como a divulgação desse projeto no jornal local Deutsche Integration.

O trabalho foi desenvolvido na Escola de Ensino Fundamental Kinderwelt, localizada no centro da cidade de Agudo. A escola atua com alunos de classe média de meio sociocultural variado.

O nome "Kinderwelt" significa "Criança-Mundo" e sintetiza o grande objetivo da escola de formar pessoas para o Mundo.

O objetivo da instituição é desenvolver integralmente a criança nos aspectos físicos, psicológicos, intelectual e social, despertando sua autonomia, criatividade, seu controle corporal e emocional, estimulando suas relações sociais para que se expresse com liberdade, criticidade e responsabilidade, valorizando assim a multiculturalidade, internalizando seu papel de agente transformador da sociedade.

O público alvo da pesquisa foram os vinte e nove alunos da Escola de Ensino Fundamental Kinderwelt: alunos do Maternal I, Maternal II, Pré-escola I e a Pré-escola II, crianças da faixa etária entre dois a seis anos.

A aplicação da pesquisa ocorreu entre os meses de agosto a outubro de 2011, por meio de momentos trabalhados numa sequência lógica de atividades desenvolvidas com as turmas de maternal e pré-escola, com o intuito de viabilizar a conscientização ambiental na Educação Infantil.

Cada momento teve, em média, duração de uma semana, e as atividades foram desenvolvidas entre as duas turmas da escola. Os temas abordados foram de grande relevância para a aprendizagem das crianças o que resultou num bom desenvolvimento das atividades.

Os momentos foram separados por atividades, mas todos tinham o mesmo objetivo: mostrar os problemas causados pelo lixo e conscientizar as crianças sobre as problemáticas ambientais.

Estes momentos surgiram das necessidades das crianças, através de curiosidades, informações trazidas de casa, temas abordados na escola e da importância da conscientização ambiental no atual momento. 
As atividades desenvolvidas tiveram um cunho prático e didático baseado nas observações e nas experiências vivenciadas pelas crianças. Todas as atividades foram desenvolvidas de forma clara e objetiva o que facilitou muito no bom andamento do projeto durante a sua execução na escola.

\section{RESULTADOS E DISCUSSÃO}

Durante o desenvolvimento do trabalho, as crianças mostraram grande interesse pelas atividades e muita curiosidade pelos assuntos abordados.

Os resultados obtidos pelo trabalho de conscientização ambiental foram alcançados durante o desenvolvimento da pesquisa e para melhor entendimento será efetuado um breve comentário sobre a compreensão dos procedimentos obtidos durante esta fase.

A escola escolhida para viabilizar a realização desta proposta de trabalho, foi possibilitada pela direção. Todos da escola se colocaram a disposição para ajudar durante o período da execução do projeto. Os professores da escola se disponibilizaram a ceder os alunos para o desenvolvimento das atividades, já que o objetivo desde trabalho também é um importante incentivo para a escola em trabalhar a questão ambiental com as crianças já que é um problema mundial que afeta diretamente a todos.

As atividades realizadas foram planejadas visando alcançar os objetivos propostos pelo projeto de pesquisa e se constituíram da seguinte maneira:

\section{- Primeiro momento}

O primeiro passo desenvolvido no projeto foi mostrar aos alunos da Educação Infantil os problemas que o lixo pode ocasionar em nossas vidas. Portanto, foi oportunizado um vídeo sobre "Natureza sabe tudo - Lixo e Desperdício", que é uma série de desenhos animados para crianças que ao mesmo tempo educa e diverte. $O$ apresentador, um pássaro chamado Albert, o Einstein da natureza, é amigável, divertido e informado sobre temas universais do meio ambiente e sabe o que é necessário para conservá-lo. O objetivo do filme foi mostrar as crianças o que é o lixo, como o produzimos e qual a sua destinação final, já que ele faz parte da história da humanidade e sua produção é inevitável. Após assistir ao filme, conversamos sobre o que as crianças entenderam do filme e para onde é levado o lixo da nossa cidade. Muitos não faziam a mínima ideia para onde ele era transportado depois de estar no caminhão.

\section{- Segundo momento}

Num segundo momento, fomos passear pela cidade para constatar se há presença de lixo nas ruas ou se a população tem a consciência de jogar seu lixo nas lixeiras para a devida destinação. Mas, o que foi constatado é que existe muito lixo espalhado pelas ruas da cidade, em terrenos baldios e pelo arroio que cruza a cidade, o que torna esta situação desagradável aos olhos dos pequenos. Além do lixo no arroio, há sérios problemas de erosão ao longo do seu leito, devido à derrubada da mata ciliar. Durante o passeio, as crianças foram, a todo o momento, instigadas a observar e perceber o que ocasionou, provocou a destruição para que estes locais ficassem dessa forma. 0 objetivo do passeio foi observar a quantidade de lixo jogado nas ruas, para que ficasse registrada a importância dessa ação, pois mostra o mundo real para as crianças. Após retornarmos a escola, foi oportunizado aos alunos para que expressassem através de desenhos o que foi visto durante o passeio.

\section{- Terceiro momento}

Após debater e discutir sobre a problemática do lixo que se encontra em nossa cidade, uma das ações concretizadas durante o projeto foi à realização da coleta de lixo na Praça Getúlio Vargas, 
local de acesso a várias pessoas que descansam, tomam chimarrão e passeiam, motivo pelo qual queríamos demonstrar que se deve manter limpos locais públicos, conseguindo, dessa forma, detectar sérios problemas sobre o lixo e propor soluções. Esta ação teve o intuito de diminuir o problema e de incentivar outras pessoas a tomar consciência dos problemas existentes e que juntos se pode amenizá-los ou solucioná-los. Assim, foram distribuídos luvas e sacos plásticos às crianças que, prontamente fizeram a coleta do lixo, que foi recolhido e jogado no seu devido lugar. Ao retornar à escola foi oportunizada uma conversa sobre a problemática do lixo e suas consequências em nossas vidas e com a paisagem. Uma das soluções encontradas pelas crianças foi à colocação de mais lixeiras nas praças e nas ruas, pois são poucas as instaladas e as que encontramos durante o passeio e na praça estão quebradas.

\section{- Quarto momento}

Após evidenciarmos os problemas causados pelo lixo e as suas consequências, foi realizada uma palestra para as crianças sobre a implantação de um Projeto de Reciclagem que acontece na Escola Estadual de Ensino Básico Willy Roos. A palestrante falou sobre a importância da reciclagem, já que o lixo é um dos principais problemas ambientais da atualidade. Além de preservar o meio ambiente, a reciclagem contribui com a diminuição significativa da poluição do solo, da água e do ar.

Outra questão levantada na palestra foi a orientação sobre a separação do lixo na escola e nas residências de cada um, demonstrando, na prática, através de embalagens vazias e questionando os alunos sobre o que é lixo e o que pode ser reciclado, para que possam estabelecer em suas casas a maneira correta de separar o lixo que pode ser reciclado do lixo que não pode ser reutilizado pela coleta seletiva, sendo o seu destino o lixão.

Após a explicação sobre reciclagem, alunos do 4ำ ano da Escola de Educação Básica Willy Roos apresentaram uma peça teatral sobre "Sapo Xexéu contra a Nhaca no meio ambiente", que tem como objetivo: colaborar com a preservação do meio ambiente; reconhecer elementos constitutivos do meio ambiente e dos meios de preservação; oportunizar aos alunos da escola de expressar os seus conhecimentos sobre os problemas ambientais; participar da dramatização empregando elementos da linguagem visual, verbal e dramática em diferentes espaços.

Para finalizar, a atividade foi divulgada no jornal da região para que todos os leitores pudessem ter acesso ao trabalho desenvolvido na escola. O objetivo do trabalho de demonstrar ações que colaboram com a preservação do meio ambiente incentiva a inserção da Educação Ambiental na Educação Infantil, sensibiliza os alunos bem como os pais e a comunidade escolar. A divulgação do trabalho para a comunidade tem por regra informar, conscientizar e mover ações desenvolvidas na escola de Educação Infantil, com o objetivo de diminuir os impactos causados pela ação do homem com o intuito de proteger a natureza.

\section{- Quinto momento}

Depois da palestra, os alunos optaram em realizar o mesmo projeto na escola, reciclar todos os materiais disponíveis e, acima de tudo, transmitir aos seus pais a importância da reciclagem. A partir desse momento, a maioria dos alunos, sensibilizados sobre a questão ambiental, começou a trazer lixo de suas casas para a escola com o intuito de implantar a reciclagem. Após essa tomada de consciência ambiental foi possível demonstrar as vantagens da reciclagem, da preservação da natureza e da não poluição do meio ambiente. O material recolhido é separado e colocado em sacos plásticos e, por último, encaminhado para as usinas de reciclagem.

Após o desenvolvimento das atividades, observou-se que as crianças demonstraram envolvimento com as ações realizadas durante o projeto, como também interesse em preservar o 
meio ambiente, já que este faz parte de nossas vidas, pois sem ele não existiríamos. As atividades foram de grande valia para a aprendizagem das crianças, pois elas não tinham nem noção sobre reciclagem e os seus benefícios para o meio ambiente.

O trabalho desenvolvido foi, sem dúvida, uma contribuição para a formação de uma consciência ecológica infantil, pois conseguiram solucionar dificuldades que encontraram em sua comunidade.

A partir desses momentos, vê-se a importância em trabalhar tais atividades com crianças da Educação Infantil, pois é nessa fase da vida que se tem o desenvolvimento e a formação da personalidade da criança, já que estão em busca do conhecimento.

Portanto, a pesquisa confirma a viabilidade de implantar a Educação Ambiental na Educação Infantil, buscando o interesse das crianças pelos assuntos relacionados à questão ambiental.

\section{CONCLUSÃO}

Após a conclusão da pesquisa, pode-se observar que o dar-se conta, a tomada de consciência ambiental na Educação Infantil permitiu uma maior reflexão, informação e discussão sobre os assuntos ligados à Educação Ambiental, permitindo que despertassem os mais variados temas sobre o meio ambiente, tornando-os mais atentos a tudo o que acontece ao seu redor.

Já que é na infância que o ser humano passa por grandes transformações em termos de atividades, de atitudes e de gestos, é necessário avaliar e perceber cada passo dessa transformação para, então, compreender as atuais necessidades de cada criança, estimulando e desenvolvendo nela uma perspectiva de uma vida adulta com características positivas sobre as suas atitudes e de si mesmo.

Assim, considera-se que os objetivos dessa proposta de trabalho foram alcançados, mas com expectativa de continuação do projeto, já que a finalidade do trabalho é contínuo na escola, ampliando e mantendo atividades, não somente na escola, mas também na comunidade escolar, a fim de que no futuro possam acontecer expressivas mudanças socioambientais dentro desta comunidade.

Mas, é importante salientar que atividades como estas não devem ser apenas trabalhadas nas datas comemorativas, como no Dia do Meio Ambiente e Dia da Árvore, e sim, deve ser trabalhado durante todo o ano letivo, pois o Planeta não suporta mais o modelo atual de desenvolvimento. E para mudar esta situação, é responsabilidade de cada um, cidadãos e educadores.

Portanto, o objetivo foi atingido com êxito, e as expectativas em despertar nas crianças da Escola de Ensino Fundamental Kinderwelt o interesse e a paixão por questões relacionadas ao meio ambiente através da inserção da Educação Ambiental na Escola de Educação Infantil. 


\section{REFERÊNCIAS BIBLIOGRÁFICAS}

BASSEDAS, E.; HUGUET, T. \& SOLÉ, I. Aprender e ensinar na Educação Infantil. Porto Alegre: Artes Médicas Sul, 1999.

BRASIL. Constituição da República Federativa do Brasil. Brasília, 1988.

BRASIL. Estatuto da Criança e do Adolescente. Brasília, 1990.

BRASIL. Lei de Diretrizes e Base da Educação Nacional. Brasília, 1996.

BRASIL. Ministério da Educação e do Desporto. Secretaria da educação Fundamental. Referencial Curricular Nacional para a Educação Infantil, v. 3, Brasília: MEC/SEF, 1998.

ELALI, G. A. O ambiente da escola - o ambiente na escola: uma discussão sobre a relação natureza em educação infantil. Estudos de Psicologia, Natal, p. $309-319,8(2), 2003$. Disponível em: <http://www.scielo.br/pdf/epsic/v8n2/19047.pdf>. Acesso em: 06 out. 2011.

GUATTARI, F. As três ecologias. 21. Ed. Campinas: Papirus, 1990.

GUIMARÃES, M. A dimensão ambiental na educação. 10. Ed. Campinas: Papirus, 1995.

JANKE, N.; TOZONI-REIS, M. F. de C. Produção coletiva de conhecimentos sobre qualidade de vida: por uma educação ambiental participativa e emancipatória. Ciência e Educação, São Paulo, v. 14, n.1, p. 147-157, 2008. Disponível em: <http://www.scielo.br/pdf/ciedu/v14n1/10.pdf>. Acesso em: 06 out. 2011.

NOAL, F. O.; BARCELOS, V. H. de L. Educação ambiental e cidadania: cenários brasileiros. Santa Cruz do Sul: EDUNISC, 2003.

RIBEIRO, M. de S. L.; PROfETA, A. C. N. A. Programas de Educação Ambiental no ensino infantil em Palmeiras de Goiás: novos paradigmas para uma sociedade responsável. Revista Eletrônica do Mestrado em Educação Ambiental, Goiânia, v. 13, jul. - dez, 2004. Disponível em: <http://www.remea.furg.br/edicoes/vol13/art8.pdf>. Acesso em: 09 out. 2011.

SCARDUA,V. M. Educação Infantil, Educação Ambiental e Educação em Valores: uma proposta de desenvolvimento moral da criança em relação às questões ambientais. Vilha Velha, 2010. Disponível em: <http://www.facevv.edu.br/Revista/04/valeriamota.pdf>. Acesso em: 06 out. 2011.

SCHÜNEMANN, D. da R. Uma proposta pedagógica de conscientização ambiental na Educação Infantil. 2010. 53f. Monografia (Especialização em Educação Ambiental) - Universidade Federal de Santa Maria, Santa Maria, 2010. 